\title{
Antonio Ruiz de Montoya y sus léxicos de la lengua guaraní: posibilidades de uso en la Historia y en la Antropología
}

\author{
Antonio Ruiz de Montoya's lexical studies of the Guarani language: \\ implementation for historical and anthropological research
}

Graciela Chamorro ${ }^{1}$

\section{Resumen}

La complexidad lingüística de una vasta región de las tierras bajas de la América del Sur fue simplificada con la adopción de una de las lenguas guaraníes como vehículo oficial de la misión y colonización en el antiguo Paraguay. En ese contexto de disminución de la diversidad e implantación de un nuevo orden social, en los léxicos escritos en guaraní y español por el jesuita peruano Antonio Ruiz de Montoya quedaron registrados importantes aspectos de la lengua y de las prácticas culturales de los pueblos indígenas, así como de la misión de los jesuitas y de la sociedad colonial en general. En este artículo tratamos de esas obras. Presentamos el autor, contextualizamos sus léxicos y ejemplificamos sus posibles usos en la investigación histórica y antropológica.

Palabras clave: Antonio Ruiz de Montoya, Tesoro de la lengua Guaraní, Historia Indígena, Antropología Indígena, Pueblos indígenas guaraní hablantes.

\begin{abstract}
The linguistic complexity of a vast region of the lowlands of South America was simplified by adopting one of the Guaraní languages as official vehicle of the mission and colonization in ancient Paraguay. In this context of reduction of the cultural diversity and of the creation of a new social order, the lexicons written in Guaraní and Spanish as recorded by the Peruvian Jesuit Antonio Ruiz de Montoya resulted in the preservation of important aspects of the language and cultural practices of the indigenous peoples as well as of the mission of the Jesuits and of the colonial society in general. In this article we consider these documents by introducing the author, contextualizing their dictionaries and exemplifying its potential uses in the historical and anthropological research.
\end{abstract}

Keywords: Antonio Ruiz de Montoya, Treasure of the Guarani language, Indigenous History, Indigenous Anthropology, Groups of Guarani-speakers.

${ }^{1}$ Profesora de la Universidade Federal de Grande Dourados; investigadora del CNPQ, Brasil. 


\section{Introducción}

Aryon Dall'Igna Rodrigues (1986: 27ss.) observó que gran parte del conocimiento histórico académico sobre los pueblos indígenas no ha aprovechado las lenguas de esos pueblos registradas en las fuentes coloniales, desperdiciándose con ello una de las vías más seguras de aproximación a la visión de mundo que esos pueblos llegaron a desarrollar, a las experiencias grabadas en sus lenguas y en su perspectiva. Semejantemente, la estudiosa eslovena que vivió en Paraguay de 1947 a 1996, Branislava Susnik, propuso que a través del estudio del vocabulario y de las frases de las lenguas indígenas se podría hacer una etnografía más segura de sus hablantes, pues existiría - en su modo holístico de comprender los humanos - un enlace firme entre cultura y sociolingüística, lo que ella sintetiza en la trilogía "pensar, hablar y actuar".

En ese sentido, los léxicos de la lengua guaraní escritos por el jesuita Antonio Ruiz de Montoya en el siglo XVII son considerados en este artículo, por un lado, como unos de los documentos más auténticos sobre el contacto, las alianzas y los conflictos trabados entre indígenas y agentes de la conquista europea. En ellos, la lengua indígena muestra aspectos del modo de vida y de las circunstancias vividas por sus hablantes hace casi cuatro siglos. Pero, por otro lado, en esos léxicos, la lengua indígena es también registro de un discurso ajeno - de un misionero jesuita peruano mestizo - sobre lo indígena. En otras palabras, en sus obras, el misionero no sólo tradujo para los indígenas el ideario cristiano y los llamó a cambiar su modo de ser, sino que también registró una serie de datos sobre la sociedad indígena en la perspectiva indígena. Eso indica, por un lado, que el interés del jesuita no se restringía a lo que él quería decir en guaraní, sino que también incluía lo que los hombres y las mujeres indígenas ya decían en su lengua. Procuramos, pues, aquí comprender lo dicho sobre el indígena, ubicando el registro de Montoya dentro del espíritu misionero y de los condicionantes y constreñimientos de aquel momento histórico e intentando demostrar las posibilidades de uso de esas fuentes en la historia indígena.

\section{El guaraní y la reducción de la complejidad lingüística en el antiguo Paraguay}

Los primeros datos sobre la complejidad étnico-lingüística en el Paraguay los debemos a los misioneros. Valgan como ejemplo los registros jesuíticos

\footnotetext{
${ }^{2}$ Al estudiar las culturas y el proceso etno-histórico de los pueblos indígenas, Branislava Susnik (1986-1987:7-12) percibió la necesidad de aproximarse a lo que denominó de "complejo verbomental" de dichos grupos étnicos proponiendo que los datos lingüísticos recogidos no se reduzcan a simples "inventarios" analíticos, sino que reflejen el comportamiento sociocultural, basado en su "pensar" y en su "hablar". Apoyada en Whorf, la autora propone que "la lengua puede moldear el pensar de sus hablantes habituales" (Susnik, 1986-1987: 8).
} 
sobre los habitantes de la región llamada Itatín, que en el tiempo de los jesuitas estaba localizada entre los ríos Paraguay, al oeste, Taquari al norte y Apa al sur (Cortesão II 1952:3), correspondiendo hoy al estado brasileño de Mato Grosso do Sul.

A inicios de la década de 1630, el misionero jesuita Diego Ferrer clasifica los pueblos que encuentra en la región en dos grandes grupos: los que hablaban guaraní y los Gualachos (Ferrer 1952 [1633]:45), agrupando bajo el nombre genérico de Gualachos "todas las naciones que no tienen por lengua propia la lengua guaraní" (ibidem, 45). Algunos de los Gualachos de Ferrer (ibidem, 4547) eran grupos chaqueños de lengua arawak (constando en su lista los Guaná, ancestros de los Terenas y Kinikinaus contemporáneos) y guaikurú (“bayas", es decir mbayá). Otros "Gualachos" vivían sobre el mismo río Paraguay, siendo los grupos payaguás sus principales integrantes; otros más al este del río, agricultores ("labradores"), pero cuyo nombre no es especificado. Once años después, otro misionero jesuita, Francisco Lupercio Zurbano (apud Pastells 1912-1933:126), lista en un catálogo diversas poblaciones indígenas que los ignacianos pretendían catequizar en el Itatín: los Cuantos, Guacamas, Guchitas y Guatos; los Nambiquaruco, Characu, Quiriquichi, Doii, Curmani; los Goñi, Cocone, Aygua, Guaquichi, Tata, Guetual, Guinchum, Cureche, Ciyu, Charare y Guayarapos. Las lenguas de la familia lingüística gualacho-arawak eran habladas por los Guanás, los Ñuguaras, esclavos de los Itatines, y los "Charare" o Xarayes; las de la familia gualachos-guaikurú eran habladas por los Mbayás, Payaguás y Guaxarapos; mientras que una de las lenguas macro-jê era hablada por los Guatós.

Esta diversidad de poblaciones y lenguas también existía en los otros frentes misioneros del antiguo Paraguay y era igualmente un desafío para los misioneros. De modo que la misión en ese contexto heterogéneo consistía de cierta forma también en una homogeneización, una simplificación de la diversidad lingüística, cultural y antropológica (Freitas 2013). Así, sobre los distintos pueblos reducidos en Chiquitos, que al fin y al cabo pertenecían a las misiones de Paraguay, consta que "se ha procurado que todos los indios aprendan la lengua de los Chiquitos" (Fernández 1726:45).

Una de las medidas que afectó negativamente la diversidad lingüística y étnica fue la política lingüística colonial definida en el Tercer Concilio de Lima (1580-1583), que, de acuerdo a la posición final del Concilio de Trento, determinó en 1583 misionar a los pueblos indios en los idiomas indígenas más difundidos, lo que recayó sobre el náhuatl en Mesoamérica, el quechua en Lima y Quito y el guaraní en Paraguay.

En consecuencia, muchas otras lenguas y variantes dialectales o formas de hablar que divergían del idioma elegido como general se han ido perdiendo. De modo que el argumento original en favor del uso de las lenguas indígenas en la 
misión - de que había que conocerlas bien para asegurar la conversión de sus hablantes - fue perdiendo sentido, pues, con el tiempo, los hablantes de esas lenguas "oficiales", a menudo, eran indígenas de otra procedencia lingüística y aprendices de las lenguas generales, que se habían tornado tan conquistadoras y colonizadoras como el castellano. No por casualidad los diccionarios, las gramáticas, los catecismos en lenguas indígenas más difundidos en el periodo colonial fueron escritos, sobretodo, en las lenguas oficiales de la misión.

Sin embargo, las mismas "reducciones guaraníticas", en verdad, nunca fueron sólo de Guaraníes, como ha sido propagado en la historiografía. En las mismas fuentes dejadas por los misioneros figuran otros pueblos indígenas que han entrado en las reducciones como hablantes de otras lenguas o con los cuales se han fundado reducciones específicas. ${ }^{3}$ Así, en 1628, en su Carta Anua al Padre Nicolás Mastrillo Durán, Provincial de la Compañía de Jesús, Antonio Ruiz de Montoya escribió desde la reducción de la Concepción de Nuestra Señora de Guañanos:

Lo primero que hiçe en pasando estos campos fue buscar un lengua Guarani que supiesse bien la Gualacha ${ }^{4}$ y deparóme Nuestro Señor un Indio tullido el qual era natural del Parana Pane y antes que nosotros entrassemos en aquel rio vino el a estas partes con animo de volverse luego, pero el Señor que le queria para maestro nuestro le tullo y asi le fue fuerga quedarse aqui entre esta jente, en donde aprendió la lengua mui bien, con ayuda deste hice Cathecismo brebe acomodado al tiempo de peste, confessionario, y despues de pasada la fuga hice un antebrebe (Cortesão I 1951: 293).

De la misma manera, en la carta de 1630 atribuida a Montoya, constan datos sobre otra lengua indígena diversa a la guaraní, "aunque no muy dificultosa a los que saben la guaraní", y se indica que el Padre Diego Salazar escribió un arte y un vocabulario en dicha lengua y que se tradujeron en ella oraciones, catecismo y cantos (Cortesão I 1951: 345-346).

En ese contexto, no podemos olvidar que los documentos en estudio en este artículo son testigos del protagonismo de los pueblos guaraní hablantes y también del silenciamiento de decenas de otros pueblos "gualachos" que se rindieron o fueron rendidos al guaraní. Cuanto al período anterior a la llegada de los conquistadores europeos, no podemos pensar que los grupos autóctonos vivían sus culturas, inmutables, en un ambiente idílico. La gran diversidad étnica conducía a intercambios, relaciones políticas, dominaciones y conflictos, en los cuales las características de los grupos eran ajustadas a la situación. Con

\footnotetext{
${ }^{3}$ Conferir al respecto el trabajo de André Luis Freitas (2013).

${ }^{4}$ La lengua "gualacha" indicada aquí en una carta de 1628 para habitantes que ocupaban el actual oeste de São Paulo no es la "de los gualachos" de Ferrer, que usó ese término genérico para pueblos que habitaban la región que hoy es el oeste de Mato Grosso do Sul.
} 
la llegada de los conquistadores esa dinámica fue alterada, acarreando nuevas prácticas y nuevas transformaciones en los modos de vida y en los procesos de producción cultural.

Se acentuaron sin duda procesos que eran sólo incipientes, o no tan fuertes, antes de la conquista. Es probable que el guaraní servía de lengua de intercambio, como el chiquito en Chiquitos, pero con los misioneros ya se volvieron verdaderas lenguas generales, en detrimento de las otras.

\section{El misionero lingüista}

Antonio Ruiz de Montoya nació en Lima, Perú, el 13 de junio de 1585. Huérfano de madre y padre, pasó parte de su infancia y adolescencia en el Real Colegio de San Martín, de Lima. Vivió parte de su juventud "esclavo de vanidades y adorador de Venus", como él mismo lo comentó años más tarde (Del Techo II 1897: 214). Ingresó en la Compañía de Jesús, en 1606. Estudió letras humanas, gramática y retórica. Como recomendado por la Ratio Studiorum, especie de matriz curricular de las instituciones jesuíticas, habrá estudiado latín por el libro De institutione grammaticae libri tres (Lisboa, 1572), del jesuita portugués Manuel Álvares (1526-1583), que ejerció gran influencia en el ámbito hispánico (Zwartjes 2000).

Según su contemporáneo y biógrafo, Francisco Jarque ([1662], 1900), Montoya llegó a graduarse como maestro en dos facultades. En 1612, fue ordenado sacerdote en Córdoba, Argentina, partiendo ese mismo año para Asunción, donde se juntó con los jesuitas que, desde 1608, estudiaban el guaraní a partir de la gramática de José de Anchieta ([1595], 1995) y los apuntes de Luis Bolaños. Este dato es importante, porque muestra que desde el punto de vista de la historiografía lingüística Montoya no empezó de cero y que su lectura de Anchieta, y tal vez de otros jesuitas de la América portuguesa, pudo haber influenciado su labor como lingüista, en vista de que el léxico religioso cristiano en tupí y guaraní, por ejemplo, son muy semejantes.

Entre los maestros indígenas de Montoya en la lengua figura el sacerdote criollo y "gran lengua" Rodrigo Melgarejo (Rouillon 1997: 68). Ya en la reducción de Loreto en el Guairá, hoy norte del Estado de Paraná, Brasil, Montoya (1989: 63) contó con la ayuda de los habitantes de la región, sobre todo, con la del "gran lenguaraz" Bartolomé Escobar, quien ya había asesorado a Fray Luís Bolaños en la traducción del catecismo recomendado por el III Concilio de Lima, el primero a ser vertido para el guaraní (Lozano II 17541755: 624).

Su progreso lingüístico mereció nota, en varias cartas jesuíticas. En la del 7 de agosto de 1613, el P. Maseta lo llama "Demóstenes en la lengua" por predicar, confesar y catequizar en guaraní (ibidem, 624). En los años siguientes, se atestigua que él "ha hecho un arte y vocabulario en la lengua guaraní" (Cartas 
Anuas II 1927-1929: 97). Es probable que hacia 1620 a esas tres obras se haya agregado el tesoro de la lengua. De ser así, y llevando en cuenta las diferencias dialectales contenidas en las obras, es probable que en un segundo momento, cuando el autor llegó a ser Superior de las reducciones del Guairá (1620) y de todas las reducciones jesuíticas del Paraguay (1636), haya incorporado en sus léxicos - escritos primeramente con datos recogidos en el Guairá, actual Estado de Paraná y oeste de São Paulo - las particularidades de las formas de hablar de los indígenas de las reducciones del Medio Paraná, hoy Misiones/Argentina, de los Tape, Paranagua y Uruguay, más al Sur del Brasil, y de los Itatines, al Norte del Paraguay y del área contigua en Brasil, hoy estado de Mato Grosso do Sul. ${ }^{5}$ En 1637, Montoya viajó a Madrid para abogar por la publicación de su obra y el derecho de uso de armas de fuego por los indígenas de las reducciones, como explicaremos brevemente.

El inicio del trabajo misionero de Montoya coincide con la promulgación de las Ordenanzas de Alfaro, el 11 de octubre de 1611. Las Ordenanzas visaban poner orden en la institución de las encomiendas ${ }^{6}$ y evitar abusos contra los indígenas (Cardozo 1991: 223). Las encomiendas pasaban entonces por su peor fase. Víctimas de todo tipo de abusos, los indígenas resistían activamente al sistema. En ese contexto, el entonces gobernador del Paraguay, Hernando Arias de Saavedra, "propuso el envío de misioneros que redujeran a los salvajes por la predicación religiosa" (Garay 1942:55-56). Los jesuitas que llegaron al Paraguay, sin embargo, se posicionaron contra la intención del gobierno y, utilizando las Ordenanzas de Alfaro como amparo legal, militaron por la integridad física de la población indígena y fortalecieron las reducciones como pueblos diferentes de los demás en su composición y en su administración. ${ }^{8}$ Lo que los idealizadores de las reducciones no se imaginaron es que las reducciones se tornarían blancos de las incursiones de los bandeirantes. ${ }^{9}$ Bajo el acoso de

\footnotetext{
${ }^{5}$ Hay quien afirma, sin embargo - lo menciona Dietrich (1995:289) -, que Montoya efectivamente haya llevado a Madrid apenas apuntes, ocupándose en la redacción y conclusión de sus obras en España.

${ }^{6}$ La encomienda era una institución de la América Española de provisión temporal de indígenas encomendados para servir a un señor encomendero, que debía catequizarlos y protegerlos.

${ }^{7}$ La conquista militar fue oficialmente prohibida por la corona español en 1573, incluso el término conquista ya no podría ser usado (Franzen 1999: 186).

${ }^{8}$ El Art. 10 prohibía la residencia de no-indígenas en las reducciones. Fuera del jesuita, ningún otro extranjero, ni el encomendero, podía dormir más de una noche seguida en ellas, como reza el Art. 11. Ya el Art. 15 establecía en torno de las reducciones zonas de seguridad, donde ningún extraño podría tener campos o ganado.

${ }^{9}$ Bandeirantes eran los integrantes de una expedición armada llamada de "bandeira" en portugués. Las expediciones partían sobre todo de São Paulo hacia el interior de Brasil, com el objetivo de capturar indígenas libres o reducidos, a fin de venderlos como esclavos en São Paulo y Rio de Janeiro (Cortesão I 1951: 492).
} 
estos brasilíndios, ${ }^{10}$ los jesuitas se dieron cuenta del efecto intimidador de las armas de fuego y pleitearon el derecho de su tenencia por los indígenas (Cartas Anuas II 1927-1929:307).

Por otro lado, las reducciones también eran acosadas por los españoles, que dependían económicamente de la mano de obra indígena, por ejemplo, para la explotación de los yerbales. En ese contexto, los jesuitas incentivaron la resistencia indígena y apoyaron la denuncia que hicieron al Rey, como consta en el acta de la asamblea guaraní de 1630 escrita en guaraní y enviada a España, acompañada de una traducción al español, probablemente hecha por Montoya. Según Melià (1998: 380), quien ha estudiado el texto completo en el original (Cortesão I 1951: 352ss) guaraní, el acta es un "temprano rescate de la lengua indígena en un discurso de alta retórica política y profundo sentido ético".

En ese ambiente de agresiva presencia de los agentes de la conquista española y portuguesa entre los indígenas, Montoya escribe al Rey: "Es imposible las reducciones en adelante guardar y defender sin defensa de armas así de fuego como las demás que usan y ejercen los vasallos de Vuestra Majestad" (Cortesão I 1951: 434).

El derecho al uso de armas de fuego fue otorgado a los indígenas, a través de Montoya, en 1644. Sin embargo, un lustro antes de recibir esa gracia de Su Majestad, el jesuita había conseguido publicar sus obras en guaraní y su crónica en castellano sobre la conquista espiritual en el Paraguay. Lograda la publicación de sus escritos, Montoya ya no esperó la decisión del Rey, en cuanto a su pedido de uso de armas de fuego, y retornó a América. Partió de Cádiz en junio de 1643 con destino a Lima, desde donde pensaba seguir hacia el Paraguay.

En los últimos años de su vida escribió una obra mística, Sílex del divino amor, obra de publicación póstuma ([1650] 1991). En ella, él recuerda las tierras por donde anduvo y deja que los ríos y sus desbordes le hablen de la vida interior. Flores y pájaros le enseñan a orar y un indígena guaraní le enseña a vivir en Dios. Era Ignacio, con apellido Paraycí en la obra de Jarque. Siete meses antes de su muerte, sin embargo, Montoya firmó un escrito mucho menos místico, su Apología en defensa de la doctrina cristiana escrita en lengua guaraní ([1651] 1996), donde polemiza apasionadamente con quienes lo censuraban en el Paraguay - especialmente con el obispo de Asunción, el fraile Bernardino de Cárdenas - a raíz de las traducciones supuestamente heréticas y escandalosas hechas por el jesuita, al verter nombres y atributos divinos al guaraní. ${ }^{11}$

\footnotetext{
${ }^{10}$ Otro nombre dado a los bandeirantes, evocando con ello la ascendencia indígena del grupo.

${ }^{11}$ La disputa giraba en torno del uso de Ta 'ýra y Membýra, que significan 'Hijo del padre' e 'Hijo de la madre' respectivamente. Para los jerarcas de la iglesia colonial, dichos vocablos indicaban semen femenino y masculino e insinuaban el acto sexual, siendo por lo tanto impropios para hablar de Jesús (Melià ([1969] 2003: 241-244).
} 
Con su opúsculo, el anciano misionero encerró su trayectoria en el campo de las letras. Reafirmó con él su aprecio por la lengua guaraní y la propiedad de sus traducciones. Falleció el 11 de abril de 1652.

Además de esas obras, Montoya escribió varias cartas, ${ }^{12}$ promovió averiguaciones (1632) (Cortesão I 1951) y redactó memoriales y peticiones (1639, 1640) (Cortesão I, 1951 y Cortesão III 1969). Sus escritos están plasmados de las cuestiones ideológicas y de los imperativos de orden práctico que dividían las opiniones de sus contemporáneos. Su gramática y sus léxicos fueron las primeras publicaciones de ese género en lengua guaraní y prácticamente las únicas disponibles en todo el tiempo colonial para quien quería aprender la lengua guaraní indígena (Melià 1998: 375) de las misiones. Hay que destacar igualmente que la labor lingüística de Montoya formaba parte de su labor política para proteger a los pueblos indígenas de los agravios de los conquistadores, puesto que, como lo ha escrito Melià (1993: 15), "no hay defensa posible de una nación indígena si se le desbarata el orden de su pensamiento y el universo de su lengua".

De hecho, su obra lingüística lo aproxima a Bernardino de Sahagún (14991540), en México, y a José de Anchieta (1534-1597), en Brasil. Como Sahagún, al afirmar que los indígenas eran "civilizables" y sostener que el cristianismo los haría más humanos, Montoya acabó registrando en su obra varios aspectos del modo de vida de los grupos guaraní. Registró también lo que debía ser combatido, sustituido y eliminado en los pueblos indígenas, así como los cambios que estaban siendo implementados en esos primeros tiempos de intenso contacto. Al igual que Anchieta, Montoya se tornó experto en la lengua indígena y maestro de varias generaciones.

\section{Los léxicos de Ruiz de Montoya}

"Tres cuerpos ofrezco impresos", escribió el jesuita al dirigirse $A$ los Padres Religiosos, en 1640. El primer tomo [cuerpo] era un Arte (A) y Vocabulario (V) de la lengua guaraní, el segundo era el Tesoro de la lengua guaraní (T), y el tercero el Catecismo de la lengua guaraní (C). De dichas obras, son sus dos léxicos los que están en foco en este artículo. En ellos ha quedado registrada la experiencia de diversos pueblos indígenas integrados a la colonia a través de las reducciones jesuíticas, entre 1612 y 1637, en la región que corresponde a los actuales estados brasileños de Paraná, Rio Grande do Sul, Mato Grosso do Sul y Oeste de São Paulo; a la hoy provincia argentina de Misiones; al Uruguay y al Oriente del Paraguay.

El Vocabulario de la lengua guaraní tiene 510 páginas a dos columnas cada una, exceptuando las dos primeras páginas. La obra está dividida en dos

${ }^{12}$ Las de 1620 (?), 1628, 1629 y 1631 están publicadas en Cortesão I, 1951; la de 1638 en Cortesão III, 1969, y la de 1645 en Cortesão II, 1952. 
partes. En la versión de 1876, utilizada en esta investigación, la paginación de la primera parte (V I) va de la página101 a la 376; la segunda parte (V II) va de la página 1 a la 234. Además de estas dos partes del vocabulario, el volumen [o cuerpo en el español de Montoya] publicado en 1640 y 1876 integra el Arte de la lengua guaraní, que ocupa las 100 primeras páginas.

El Tesoro es más extenso, consta de 408 hojas, folios, a cuatro columnas, más las diez páginas iniciales no paginadas. "Comprende 5.500 entradas, más unas 580 palabras que no tienen entrada propia, sino que se hallan escondidas en otras entradas del Tesoro o en el Vocabulario", escribió Wolf Dietrich (1995: 291), en base a los estudios de León Cadogan (1962-1963: 517-532).

En su conjunto los dos léxicos de Montoya tienen un carácter mixto: son diccionarios de la lengua, pues indican peculiaridades lingüísticas de las voces que registran, pero no sólo presentan palabras con función designativa, sino también artículos, pronombres, adverbios, preposiciones, conjunciones e interjecciones. Dada la riqueza de sus datos se puede hablar de una gramática implícita del guaraní en esos léxicos. ${ }^{13}$ Por otro lado, los léxicos, especialmente el Tesoro, son diccionarios de cosas, pues amplían la información sobre las palabras, indicando sus diversos significados y ejemplificando sus usos. En el caso de algunos sustantivos y expresiones - como teko, 'modo de vida', ára, 'tiempo-espacio', yvy, 'tierra', y, 'agua', kuña, 'mujer', kuimba'e, 'hombre' - esas explicaciones son tan extensas, que el Tesoro merece el atributo de "enciclopédico".

En cuanto al género y contexto de los dos léxicos, hay que recalcar que Vocabulario fue el nombre dado en la fase inicial de la Edad Moderna no sólo a los registros lexicográficos hechos en España, sino también a los registros hechos en las colonias ibéricas. Sirvan como ejemplo los registros del quechua de Domingo de Santo Thomás y Diego González Holguín. Las obras sobre el guaraní siguieron la misma nomenclatura.

El Vocabulario escrito por Montoya es una obra relativamente sencilla, que consiste en un listado de palabras y expresiones en español con su equivalente en guaraní. Conociendo el término o la expresión en la lengua de destino, la persona interesada en obtener más datos tendría que recurrir a continuación al Tesoro, donde son presentados la composición, los significados y usos de los términos y expresiones, como aclaró Montoya en su Advertencia 1 y 7 (V I: 4-5): "En este Vocabulario se ponen los vocablos simplemente. Para saber sus usos y modos de frases, se ha de ocurrir a la segunda parte [el Tesoro] (...) busco aquí Hombre, hallo que es Abá, buscaré Abá en la segunda parte, y allí hallaré lo que se dice del hombre". En las palabras de Melià (2002: XIII), "el Vocabulario es un instrumento para que el castellano pueda requerir su correspondencia en

\footnotetext{
${ }^{13}$ Valdría la pena complementar el Arte de Montoya con los datos gramaticales contenidos en los léxicos.
} 
guaraní”. Hallada esta correspondencia, está indicado el camino para llegar a la lengua como tal. De modo que "todo el Vocabulario lleva en dirección al Tesoro". El guaraní es, en última instancia, la lengua de destino de estos léxicos. En sus "Advertencias" al Tesoro, Montoya retoma el tema al afirmar:

Toda esta lengua está llena de figuras y metáforas, que los muy versados en ella se ven muy atajados, por no caer fácilmente en la traslación o metáfora, y así se ha procurado todo lo posible poner el uso de ellas. De donde saldrá no juzgar fácilmente por no lengua, o por no usado el vocablo que no se entiende. Por la misma razón podrá ser que queriendo averiguar algún vocablo con los mismos naturales (simplemente) lo extrañe; pero dicho con sus circunstancias y aun con su donaire (que todo es menester) lo entiendan y conozcan por muy elegante, $\mathrm{cm}$ frecuentemente pasa (T:1).

En cuanto al método usado para la confección de sus léxicos, es probable que Montoya se basara en los escritos de su época sobre otras lenguas indígenas, como el Arte de José de Anchieta para la lengua tupinambá, las anotaciones del franciscano Luís Bolaños, los borradores de una gramática guaraní escrita por el Padre Alonso de Aragona y otros manuscritos dejados por los misioneros del Brasil, que no fueron publicados. Hay que imaginarse al joven Montoya reuniendo sus datos inicialmente mediante el aprovechamiento de esos textos ya existentes. Lo mismo se puede decir de la estructura de su obra. Es probable que él se haya inspirado también en trabajos hechos para el quechua por los frailes Domingo de Santo Thomas y Juan Martínez y el padre Diego González Holguín, que fue rector (1610-1613) del colegio jesuítico en Asunción y estudioso del guaraní. Sin embargo, según Melià (2002:X), una dependencia más directa de este último tiene que ser descartada. Un análisis comparativo del Vocabulario de Montoya y el de González Holguín muestra que "cada uno ha seleccionado la lista de palabras y los campos semánticos de una manera muy personal" (Melià 2002:X).

De lo que no podemos dudar es que Montoya, intencionalmente o no, usó para la lengua guaraní un método muy parecido al usado por González Holguín para el quechua. "Esta obra [no es] mía principalmente sino de los muchos indios del Cuzco a quienes yo he repreguntado y averiguado con ellos cada vocablo [...]", escribió el compilador de la "lengua general de todo el Perú". ${ }^{14}$ De modo semejante, Montoya atestigua que él accedió a sus datos recurriendo a un equipo de lenguaraces guaraníes, que le instruyeron especialmente en la descripción semántica de las palabras. "Dio finalmente fin a este trabajo el tiempo de treinta años que he gastado entre Gentiles [...] con eficaz estudio rastreando lengua tan copiosa y elegante que con razón puede competir con las de fama [...]. He tenido por intérpretes a los naturales", escribió al dirigirse $A$ los

${ }^{14}$ González Holguín, citado por Melià 2002:IX. 
Padres Religiosos en las primeras páginas de su Tesoro. Otro de sus ayudantes fue el sacerdote criollo Rodrigo Melgarejo, "gran lengua y pretendiente de la Compañía” (Rouillon 1997:68), quien lo asesoró durante su estadía en Asunción. Ya en la reducción de Loreto se destacó entre sus asesores el lenguaraz capitán Bartolomé de Escobar, que ya había asesorado a Fray Luís Bolaños.

En cuanto al género Tesoro, ${ }^{15}$ cabe destacar que ese (Thesaurus) fue primeramente el nombre dado a los diccionarios monolingües en la época renacentista, siendo entonces un instrumento lexicográfico muy extenso, que se basaba en un gran número de citas, generalmente de prosistas y poetas considerados representativos o ejemplares en cuanto al uso de los términos que se quería explicar (Hänsch e.a. 1982:108). Entre los tesoros monolingües, aquí nos interesa de forma especial el Tesoro de la lengua castellana o española del licenciado Sebastián de Covarrubias Orozco, de 1611, que, por un lado, es un diccionario lingüístico porque explica palabras, frases, refranes, etc. y, por otro lado, es un diccionario enciclopédico porque reúne datos sobre la cultura de la época (Haensch 1982:109).

Que Montoya haya conocido el Tesoro de Covarrubias estando aún en Paraguay es improbable, pero sin duda lo utilizó en España, inspirándose en él para intitular el segundo cuerpo de su obra. Basamos esta hipótesis sobre el hecho de que, estando en América, Montoya no llegó a llamar Tesoro a su léxico guaraní-castellano, que, sin embargo, acabó siendo publicado bajo ese título en Madrid (Melià, 2002: X). Otro episodio curioso es que Montoya haya hecho publicar su Tesoro por la misma persona que había editado, 28 años antes, el Tesoro de Covarrubias, o por alguno de sus familiares (Dietrich 1995: 291, nota $5)$.

Unas décadas después de la publicación del primer tesoro monolingüe, se empezó a designar con el término tesoro también diccionarios plurilingües en Alemania, Francia y España, como el Tesoro de las dos lenguas francesa y española, de César Oudin, publicado en 1607. Aunque el título no lo explicite, el Tesoro de la lengua guaraní de Montoya se inscribe entre los tesoros plurilingües, pues da el significado de las palabras y frases guaraní en castellano, además de explicar su composición y ejemplificar sus usos. Aun así, la calidad de tesoro de este léxico se refiere al guaraní y no al castellano.

El término tesoro sugiere la idea de que el diccionario es una fuente de riqueza. Montoya (T:A los Padres Religiosos) lo expresó claramente al explicar que llamó tesoro al segundo tomo de su trilogía, porque en él procuraba vestir

\footnotetext{
${ }^{15}$ El término fue usado por primera vez por el humanista francés Robert Estienne, conocido también como Stephanus, en su Latinae Linguae Thesaurus de 1531 (Dietrich 1995: 291, nota 5). Posteriormente, Jean Nicot lo ha utilizado en el primer diccionario monolingüe del francés, en su Thresor de la langue françoysetant ancienne que moderne (1606). Figura también como Tesoro la obra de Henri Estienne, Thesaurus graecae linguae, de 1572.
} 
las palabras "con algo de su riqueza", que él ha podido "sacar de su mineral rico". En el caso del Tesoro de la lengua guaraní, sin tradición literaria en la época en que fue elaborado, la lengua guaraní era una lengua viva. Él se basó en quienes hablaban la lengua. Dietrich considera "rica" la fraseología contenida en él, sea para el estudio del uso de las formas o del sentido de las palabras.

En resumen, el Tesoro es mucho más extenso que el Vocabulario y lo complementa. Según Melià, en el Tesoro, más que en otro diccionario, las palabras "pierden la abstracta neutralidad de la sola nomenclatura", al ser explicadas con frases y dichos que "reflejan situaciones de vida guaraní típicas y originales" (Melià 1992:90).

\section{La geografía de la lengua y de los pueblos}

Es probable que los cronistas de la conquista y de la colonia denominaran a los grupos indígenas que iban contactando según su autodenominación local. Es lo que sugieren los nombres alusivos a ríos y/o a caciques con que fueron registrados varios grupos en los documentos coloniales: Cario, Carijó, Tobatín, Guarambaré, Itatín, Parayguá, Uruguayguá, Tape, Guayrá, Arechané, Caaró, Tarumá, Chiriguano y Chadul o Guaraní de las islas. ${ }^{16}$

Isabelle Combès, en comunicación personal, apunta para un criterio muy importante usado por los españoles para denominar los pueblos indios: la lengua que hablaban. Para ella, sólo así se explica el hecho de que todos los grupos que hablaban más o menos como los de las islas del Paraná acaben siendo "guaraní". Combès también destaca que los conquistadores les daban a los pueblos que iban contactando los nombres que les daban sus guías. Los "Chiquitos", por ejemplo, fueron llamados así porque los guías de los españoles eran Guaraníes, y éstos les decían tapy'ýi mirî, esclavos pequeños.

En otros casos, los pueblos indígenas se designaban a sí mismos, o se los designaba añadiendo a un sustantivo, relativo a la geografía del lugar, el sufijo -guára, que significa 'procedente de'. Así, yvyty riguára eran 'quienes moraban en la sierra' (V II: 192), ko yguára 'quienes vivían en las inmediaciones de un determinado río' (T: 163), yry kuapeguára 'quienes ocupaban la cabecera de un río' (T: 164) y paraguaygua 'quienes vivían a la orilla del río Paraguay o en Asunción' (T: 263). Es interesante observar que la pregunta ¿de dónde eres? se vierte al guaraní diciendo mamoyguára pende (T: 205), que significa 'de cuál río eres' o más poéticamente ¿de qué agua bebes? Lo que puede indicar que los guaraní hablantes vivían generalmente en las matas cercanas a los ríos.

Los guaraní hablantes también demarcaban su identidad social usando ñande o ñandéva y ore u oréva, pronombres de la primera persona del plural,

\footnotetext{
${ }^{16}$ Basado en Muraro et alii (1987, índice temático) y en Susnik (1982:32-35), aunque con variaciones.
} 
'nosotros', incluyendo el primero al interlocutor y excluyendo el segundo (T: 241). Así, ñande aipóva'e significa 'es de los nuestros, es nuestro pariente' (T: 242) [tuyo también] y ore reheguára 'los nuestros' (T: 258) [pero no tuyos].

La idea de pertenencia a una parcialidad es indicada por el término te'ýi (re'ýi, he'ýi, gue'ýi) (T: 376). Que los de una parcialidad vivían juntos es muestra la expresión oro re'ýi a'e oroiko (T: 376). Te’ýi es también el lexema usado para formar el término esclavo. Tapy'ýi se compone de tapy, 'cosa comprada' y te'ýi 'generación, familia, descendencia'. Según Montoya, por tapy'ýi llamaban los Guaraníes a las demás naciones (T: 355), entiéndase, a aquéllas que integraban el "nosotros" guaraní, en la condición de esclavos.

Por otro lado, a medida en que los cronistas fueron realizando comparaciones, llegaron a designar a los grupos y a las lenguas habladas por ellos con términos más genéricos, ${ }^{17}$ según su importancia en la región. En ese sentido y considerando el caso específico de este trabajo vale mencionar el testimonio de Montoya respecto a las lenguas habladas por los pueblos agrupados bajo los nombres "tupí” y "guaraní”. Según él, esas tribus hablaban una única lengua: "Tan universal, que dominaba ambos mares, el del Sur por todo el Brasil, y costeando a todo Perú, con los dos mayores ríos que conoce el planeta, que son el de La Plata, cuya desembocadura en Buenos Aires es de ochenta leguas y el Gran Marañón, que no le es inferior en nada, que pasa muy cerca de la ciudad de Cuzco, llevando sus aguas al Mar del Norte" (T: A los padres religiosos).

Al demarcar ese inmenso territorio ocupado, aunque no de forma ininterrumpida, por grupos "guaraní" y "tupí", Montoya no desconsideraba las diferencias dialectales entre las lenguas habladas por esos grupos, ya que en sus Advertencias él ponderó que algunos vocablos eran más usados en unas partes que en otras y que el hecho de haber registrado todos los que pudo era "para que no se haga nuevo al que oye en una parte el vocablo que en otra no oyó" (T: 1). El hecho de referirse a ellas en singular sugiere que en su evaluación esas diferencias se daban en el ámbito de una única lengua. Por otro lado, al situar esa lengua en la vasta área de las tierras bajas, quería él probablemente enaltecer y afirmar como lengua general la lengua hablada en el Guairá, que es la que le fue más familiar y la que él más usó en su labor. Mostraba, así, la importancia de esa lengua y lo vasto de su tarea misionera.

Pero no todo es muy claro en la terminología usada por Montoya. En su Apología [1651], él menciona a naciones "tupí" y "guaraní", como gente "paraguaya", "brasilera" y "del Marañón" (Ruiz de Montoya 1996:93), pero llama "guaraní" inclusive a las lenguas habladas en Brasil y en el "Gran Marañón" (T: A los padres religiosos). Como ya hemos visto, Montoya y los jesuitas contemporáneos a él entraron en contacto más precisamente con

${ }^{17}$ Historiadores como el Padre Astrain (1995: 72) consideran "vago" el nombre "guaraní". 
pueblos guaraní hablantes del Itatín, Guairá, Paraná, Tape y Uruguay y con pueblos hablantes de otras lenguas indígenas en las reducciones, que, como hemos visto, nunca fueron sólo de Guaraníes, como ha sido propagado en la historiografía.

Pero además de todos estos nombres que tienen como referencia o son relativos explícitamente a pueblos hablantes de lenguas del tronco tupi, Montoya registró en sus léxicos otros nombres dados a otros pueblos, geográfica y/o lingüísticamente identificables o no. Así, si buscamos montaraz en su Vocabulario de la lengua guaraní, encontraremos ka'ayguára, ka'apeguára (V II: 99), que significa salvaje, sea por proceder de o por vivir en la selva. Ka'ayguára o ka'apeguára es sinónimo de anãmi (B II: 185), nombre dado por los guaraní hablantes 'en algunas partes a los indios bravos salvajes' (T: 34). También lo es de re'a, que significa 'del campo' mas es traducido por 'bárbara gente' (V I: 206). Otro término peyorativo usado como "etnónimo" es apysa 'ỹre [apysaire], que indica primeramente 'privación', ' $\tilde{y}$, del 'oír', apysa, y luego, por la identificación del sentido del oír con el entendimiento, 'hombre obstinado, perverso, que no se guía por la razón'. Este sentido era transferido a cierta parcialidad de indios, que para los guaraní hablantes comían fuego y tenían pacto con el demonio (T: 54).

La alteridad es registrada también en expresiones como ojohúamo kyvõnguára, 'los países de acá' (T: 129, 159), ojosúamo reheguára, 'los de su parcialidad de ellos o de aquella región' (T: 129). Entre los de "aquella región" constan los del Perú, Karakara retãma (T: 90); los 'marítimos', parapeguára, y 'los de la otra banda del mar' para mboypyrigua (T: 129). Y entre estos están 'los de la corte' española [nuestros verdaderos amos], ñande ruvichavete retãmeguára (T: 129); los 'españoles', llamados karai (T: 231) o mbai. Sobre el origen de este último, Montoya, algo jocosamente, escribió que se ha "sacado de este nombre mbaipýra - mazamorra - porque dicen que antiguamente mataron a un español y se lo comieron cocido y del caldo hicieron mazamorra". El hecho acabó en proverbio - abiit in pro marbium - (T: 212).

Pueblos que aparentemente nada tenían que ver con la experiencia reduccional en el Paraguay son contemplados igualmente con algunas expresiones en los léxicos, ciertamente por iniciativa y necesidad del autor jesuita y no de las comunidades indígenas. Una expresión relativa a los orientales es Kuarasy sẽmbápeguára, 'los de la naciente del sol' (T: 328). Los ingleses son registrados como ajuru ju (T: 29), siendo que ju, 'amarillo' hace referencia al cuello, aju.r, de la persona o de alguna vestimenta o a la piel clara de tales habitantes.

Los negros, que servían en algunas reducciones como esclavos, son referidos como tapañũ ñemoñãngáva, 'descendencia de negros' (T: 229). La conciencia de que había muchos pueblos es indicada por ijype ype vetei ava, hay muchos países de gente (T: 176). En el contexto reduccional, esa diversidad 
es considerada de origen divina, ñemoñãnga'e nga'e heta Tupã yvýpe omõi, 'Dios ha puesto en la tierra muchas naciones o castas' (T: 229).

\section{Sitios arqueológicos de palabras}

Nos gustaría finalizar este artículo insistiendo sobre el carácter enciclopédico de los léxicos en foco. Al hacerlo, nos unimos a Melià, quien desde hace décadas destaca la riqueza de esas fuentes y aboga por la necesidad de su utilización en los estudios histórico-antropológicos. Para él, estas fuentes son etnográficamente tan vastas, que cubren casi todo el cuestionario científico (Melià 1988:43). El índice temático resumido al final del libro Decir el Cuerpo (Chamorro 2009) ha sido elaborado siguiendo el Manual de Etnografía de Marcel Mauss (1993), mientras la autora leía los léxicos de Montoya. ${ }^{18}$ Esa experiencia de lectura ha sido como un trabajo de campo en el pasado, como si se leyese el diario del misionero. En sus léxicos, Montoya no sólo aprendió y reprodujo el habla de sus interlocutores e interlocutoras indígenas, sino que también lo interpretó y

${ }^{18}$ Los tópicos trabajados así como el listado presentado en el libro (Chamorro 2009: 371-394) se dejan resumir de la siguiente forma: El cuerpo humano: los órganos y sus funciones; ciclos de vida; erotismo, sexualidad, reproducción; aspectos y disposiciones físicas y sicológicos de la persona; indicadores de creatividad y destructividad; estados de consciencia e inconsciencia; fenómenos oníricos; sentimientos, emociones y disposiciones anímicas; salud, enfermedad y muerte.

La subsistencia: técnicas mecánicas, máquinas y otros implementos, el fuego, venenos y otras substancias químicas; técnica de la piedra, de la madera, del cuero, del tejido y del trenzado, del barro, del refinado y de la terminación; de la restauración y la pintura. La guerra: enemigos, armas, tácticas. La culinaria: alimentos; residuos y basuras, tipos de comidas y bebidas, sabores, ideologías, condimentos y esencias aromáticas. Caza, colecta y pesca: tácticas, artificios e implementos. Domesticación de animales y plantas; especies cultivadas, el plantío, la cosecha. El vestuario. Las casas: tipos, funciones y técnicas. Muebles y utensilios. La locomoción y el transporte.

La organización social: Auto-denominación indígena, denominación atribuida, los otros; diversos actores sociales y formas de relacionamiento; la familia nuclear y extensa; el parentesco; orfandad y viudez; espacios sociales. Liderazgo y administración; jerarquías; líderes nuevos y tradicionales; formas de ejercer la autoridad; autoridades judiciales y sus funciones; la ley; los crímenes; la prisión; castigos. Prácticas económicas: trabajo, propiedad, comercio, moneda, reciprocidad. Educación: el conocimiento, formas de aprender y enseñar, educación escolar. Actividades recreativas: juegos orales manuales y corporales; juguetes. Las artes: decoración corporal; ornamentación del ambiente; pintura, escultura, música, poética. La comunicación: idioma, lengua, lenguaje; tipos o géneros del decir; el correo; malas y buenas palabras; traducción e interpretación. El tiempo: diversas formas de pasado, de presente y futuro; la duración y la frecuencia; el tiempo físico; tiempo y espacio; memoria y tiempo; el fin. El ambiente: orientación espacial; caminos; límites; tipos de suelo; el agua; accidentes geográficos; el espacio sideral; fenómenos meteorológicos. Religión/Cosmología: representaciones materiales de seres divinos; los seres humanos; rituales; religión indígena; rezos, profecías y predicciones; vestimentas y objetos litúrgicos; conceptos teológicos; el mal y los pecados; liderazgo religioso; lugares sagrados. 
lo aproximó a otro universo de significados. A las comunidades indígenas les enseñó a nombrar y definir nuevas grandezas y a resignificar o redefinir lo que ya decían.

Como los léxicos estudiados son bilingües, el primer marcador de esa interferencia es la propia lengua castellana; el segundo, la religión cristiana en su versión católico-romana postridentina, y el tercero, la mentalidad conquistadora y reductora imperante en todos los ambientes de la época. En el estudio aquí propuesto, esos marcadores son identificados y analizados para extraer de ellos los significados y las implicaciones, muchas veces poco explícitos, que pueden ayudar a comprender tanto la ideología misionera como las prácticas culturales de los pueblos indígenas misionados. Con ello, entendemos que los diccionarios no son sólo depósitos de palabras o inventarios de unidades léxicas. Además de revelar el universo semántico-cultural de una sociedad, también son vehículos de representaciones ideológicas; por un lado, del individuo o grupo enunciador $y$, por otro, de la comunidad de hablantes (Bassani 2003: 159-160).

Cabe mencionar que Melià, quien fue el primero en proponer esta lectura y este uso de los datos reunidos por Montoya en sus léxicos, ha escrito diversos trabajos sobre la metodología (Melià 1988) y sobre diversos temas, como la tierra sin mal (1987) y el trabajo (1989). Sus obras han impulsado la disertación de Francisco Noelli (1993: 159-237), lamentablemente aún no publicada. En este texto el autor, apoyándose sobre datos arqueológicos y en lo que los diccionarios de Montoya registraron sobre la cultura material de los pueblos indígenas, estudia los artefactos relacionados con la subsistencia, destaca la fabricación y el uso de implementos como arcos y flechas, arcos de bolas, lanzas, diversos tipos de armadillas e instrumentos para cazar y pescar; también detalla y clasifica los instrumentos y herramientas domésticos en función de su materia prima (cuero, madera, piedra, hueso, conchas y metales) y de su forma y uso (tipos de cestos y utensilios cerámicos). Noelli también ha estudiado los recursos naturales, su manejo y uso por los indígenas. Otros, como André Soares (1997), Graciela Chamorro (1995, 2008, 2009) y Antonio Caballos (2011), siguiendo la misma orientación, han usado los léxicos de Montoya en sus investigaciones etnohistóricas sobre los pueblos indígenas del siglo XVII, intentando mostrar la etnografía implícita en esas fuentes: Soares, sobre la organización social; Chamorro, sobre el lenguaje religioso, el tiempo y el cuerpo humano; y Caballos sobre el panorama etnográfico. Entre otros trabajos, estos han mostrado que los escritos de Montoya son como sitios arqueológicos de donde pueden extraerse datos valiosos para el conocimiento de los modos de vida del pasado y una aproximación más fundamentada de los hablantes - sobre todo indígenas - de la lengua guaraní en el presente.

Las fuentes aquí estudiadas, como las otras obras lexicográficas producidas en el continente americano en la época inicial de la colonia, precisan ser situadas 
en el contexto del avance de la escritura sobre la palabra. Aplicando a ello lo escrito por León Portilla (1997:11), se diría que se trata del "proceso de aprisionar con signos escritos lo que anteriormente, a través de siglos, repetía el pueblo de viva voz". Las obras de Montoya fueron escritas con la intención de "legitimar" la lengua hablada a través de la escritura, para "estabilizar" y "estandarizar" las muchas formas de hablar de los pueblos indígenas, para facilitar el aprendizaje de las lenguas indígenas a los misioneros de la época y a los de las futuras generaciones. Pero en esas obras también quedaron sedimentadas no solo las formas de hablar y de nombrar sino también la cultura y la visión de mundo de generaciones de indígenas y de misioneros. Estos últimos fueron primero neófitos en las lenguas americanas y en todo lo que ellas representaban, mostrando posteriormente una profunda inserción y un vasto conocimiento de la nueva lengua. Antonio Ruiz de Montoya muestra una serie de elementos que, en rigor, ni él ni sus compañeros necesitaban conocer para realizar su misión. Los registra porque estaba interesado no sólo en lo que él mismo quería decir en guaraní, sino también en lo que los indígenas ya decían. Quería mostrar también la complejidad de sus expresiones culturales, como prueba de su civilización.

Como la lengua guaraní es una lengua viva hasta el presente, siendo hablada por varios grupos indígenas contemporáneos, el uso de los léxicos de Montoya no puede prescindir del aporte de los grupos guaraní actuales y de los etnografados en las últimas décadas, lo que propiciaría un diálogo contrastivo sui generis entre los registros históricos y la producción etnográfica actual.

\section{Referencias}

\section{Fuentes primarias}

Montoya, Antonio Ruiz de. [1651]. 1996. Apología en denfensa de la doctrina cristiana escrita en guaraní. Lima/Asunción: Centro Amazónico de Antropología y Aplicación Práctica/Centro de Estudios Paraguayos "Antonio Guasch".

. [1640], 1993. Arte de la lengva gvaraní. Asunción: Centro de Estudios Paraguayos "Antonio Guasch".

. [1640], 1876a. Bocabulario de la lengua guarani. Leipzig: Oficina y funderia de W. Drugulin, 1876aI, 1876aII.

. [1640], 1876b. Catecismo de la lengua guarani. Leipzig. Oficina y funderia de W. Drugulin.

[1639], 1989. Conquista espiritual hecha por los religiosos de la Compañía de Jesús en las provincias del Paraguay, Paraná, Uruguay y Tape. Estudio Preliminar y notas: Dr. Ernesto Maeder. Rosario: Equipo Difusor de Estudios de Historia Iberoamericana. 
[1650], 1991. Sílex del divino amor. Introducción, transcripción y notas de José Luis Rouvillon Arróspide. Lima: Pontificia Universidad Católica del Perú / Fondo Editorial.

. [1639], 1876c. Tesoro de la lengua guarani. Leipzig: Oficina y funderia de W. Drugulin.

. [1640], 2002. Vocabulario de la lengua guaraní. Transcripción y transliteración Antonio Caballos; Introducción Bartomeu Melià. Asunción: Centro de Estudios Paraguayos Antonio Guasch.

. [1639], Tesoro de la lengua guaraní. Presentación por B. Melià. Transcripción y transliteración por Friedl Grünberg, con la colaboración de B. Melià. Asunción: Centro de Estudios Paraguayos Antonio Guasch.

\section{Bibliografía de comparación y análisis}

Anchieta, José de. [1595], 1990. Arte de gramática da Língua mais usada na costa do Brasil. Ed. fac-similar. São Paulo: Loyola. (Obras completas, 11).

Astrain, Antonio. 1995. Jesuitas, guaraníes y encomenderos: Historia de la Compañía de Jesús en el Paraguay. Asunción: Centro de Estudios Paraguayos "Antonio Guasch".

Bassani, Sandra Mara M. S. 2003. O dicionário como veículo de representações ideológicas: uma análise empírica com pontos e contrapontos. Anuário brasileño de estudios hispánicos, (13): 159-169.

Cadogan, León. 1962-1963. Registro de algunas voces internas del Tesoro de la lengua guaraní del P. Antonio Ruiz de Montoya, S.J. Bulletin de la Faculté des Lettres de Strasbourg, 3(8): 517-532.

Cardozo, Efraim. 1991. El Paraguay colonial. Asunción: Edición El Lector.

Cartas Anuas I - Cartas Anuas II: Cartas Anuas de la Provincia del Paraguay, Chile y Tucuman de la Compañia de Jesus. 1927-1929. Con advertencia de Emilio Revignani e introducción de P. Carlos Leonhardt. Buenos Aires: Talleres Casa Jacobo Peuser; 2 tomos. (Documentos para la Historia Argentina, Tomos XIX e XX).

Covarrubias Orozco, Sebastián. [1611], 1995. Tesoro de la lengua castellana o española. Madrid: Editorial Castalia.

Cortesão, Jaime. 1951. Manuscritos da Coleção de Angelis, tomo I: Jesuitas e bandeirantes no Guairá (1549-1640). Rio de Janeiro: Biblioteca Nacional.

. 1952. Manuscritos da Coleção de Angelis, tomo II: Jesuitas e bandeirantes no Itatim (1596-1760). Rio de Janeiro: Biblioteca Nacional.

. 1969. Manuscritos da Coleção de Angelis, tomo III: Jesuitas e bandeirantes no Tape (1615-1641). Rio de Janeiro: Bibiloteca Nacional.

Chamorro, Graciela. 2002. Reaccion a la conferencia de Bartomeu Melia "La Iglesia en la visión de los Indios" In: 500 Anos de Brasil e Igreja na America Meridional. Porto Alegre: EST Edições; pp. 26-39.

2009. Decir el cuerpo. Asunción: Tiempo de Historia. 
2007. Antonio Ruiz de Montoya: Promotor y defensor de lenguas y pueblos indígenas. História Unisinos 12:35-54.

. 1995. Kurusu Ñe'ëngatu, palabras que la historia no podría olvidar. Asunción/ São Leopoldo: CEADUC/IEPG, COMIN.

. 2008. Terra Madura Yvyaraguyje: Fundamento da Palavra Guarani. Dourados: Editora da Ufgd.

Del Techo, Nicolás del. 1897. Historia de la Provincia del Paraguay de la Compañía de Jesús. 5 tomos. Madrid: Librería y Casa Editorial A. de Uribe y Compañía.

Dietrich, Wolf. 1995. La importancia de los diccionarios guaraníes de Montoya. Amerindia, Revue d'Ethnolinguistique Amérindienne, "La 'découverte' des langues et des écritures d'Amérique". AEA, Centre National de la Recherche Scientifique, pp. 287-299.

. 2000. La sintaxis en las primeras gramáticas del guaraní y del quechua. In: Beatrice Bagola (ed.). La lingüística española en la época de los descubrimientos. Hamburgo: Helmut Buske Verlag; pp. 31-42. (Anexo 5 a Romanistik in Geschichte und Gegenwart).

Fernandéz, Juan Patricio. 1726. Relación historial de las misiones de los indios que llaman Chiquitos, que están a cargo de los padres de la Compañía de Jesús de la provincia del Paraguay. Escrita por el padre Juan Patricio Fernández, de la misma Compañía. Sacada a luz por el padre Gerónimo Herrán, procurador general de la misma provincia. Madrid: Imprenta de Manuel Fernández.

Ferrer, Diogo. [1633]. 1952. In: Cortesão II 1952. Manuscritos da Coleção de Angelis, tomo II: Jesuitas e bandeirantes no Itatim (1596-1760), Rio de Janeiro: Biblioteca Nacional.

Franzen, Beatriz Vasconcelos. 1999. Os jesuitas portugueses e espanhóis e sua ação missionária no Sul do Brasil e Paraguai (1580-1640): um estudo comparativo. São Leopoldo: Ed. Unisinos.

Garay, Blás. 1942. Tres ensayos sobre historia del Paraguay. Asunción: Guarania.

Haensch, Günter et alii. 1982. La lexicografía: de la lingüística teórica a la lexicografía práctica. Madrid: Gredos. (Románica hispánica 56).

Jarque, Francisco. [1662], 1900. Ruiz de Montoya en Indias. 4 tomos. Madrid: V. Suárez.

Lozano, Pedro. 1754-1755. Historia de la Compañía de Jesús de la Provincia del Paraguay. 2 tomos. Madrid: Impr. de la viuda de M. Fernández.

Mauss, Marcel. 1993. Manual de Etnografia. Lisboa: Ed. Dom Quixote.

Melià, Bartomeu. 1987. La tierra sin mal de los Guaraníes, economía y profecía. Suplemento Antopológico, Asunción: CEADUC, 22(2):81-98.

. 1988. El guarani conquistado y reducido; ensayos de etnohistoria. 2a. ed. Asunción: Centro de Estudios Antropológicos de la Universidad Católica. (Biblioteca Paguaya de Antropología, 5). 
. 1989. Potyrõ: a questão do trabalho indígena guarani. In: Anais do VIII Simpósio Nacional de Estudos Missioneiros; p. 295-326.

. 1992. La lengua guaraní del Paraguay: Historia, sociedad y literatura. Madrid: Mapfre. (Lenguas y Literaturas Indígenas, 6).

. 1993. Antonio Ruiz de Montoya y el Arte de gramática de la lengua guaraní. In: Antonio Ruiz de Montoya. Arte de la lengua guaraní. Asunción: Centro de Estudios Paraguayos “Antonio Guasch”.

. 1998. Antonio Ruiz de Montoya y la construcción de una lengua guaraní en el Guairá. Jornadas Internacionais sobre as missões Jesuíticas: As Missões Jesuíticas Del Guairá. Cascavel, Unioeste; pp. 365-390.

2002. A modo de introducción. In: Montoya, 2002, pp. V-XIX.

. [1969], 2003. La lengua guaraní en el Paraguay colonial. Asunción: CEPAG.

Muraro, Valmir, Marcos Vinicius de Almeida Saul, Bartomeu Melià. 1987. O Guarani; uma bibliografía etnológica. Santo Angelo: Fundames.

Noelli, Francisco Silva. 1993. Sem tekoha não há teko; em busca de um modelo etnoarqueológico da aldeia e da subsistência e sua aplicação a uma área de domínio no Delta do Rio Jacui - RS. Dissertação de Mestrado. Porto Alegre, PUCRS; 2 tomos.

1999. Aportes históricos e etnológicos para o reconhecimento da classificação guarani de comunidades vegetais no século XVII. Fronteiras, 3(4): 275-96.

Pastells, Pablo. 1912-1933. Historia de la Compañía de Jesús en la Provincia del Paraguay. Según los documentos originales del Archivo General de Indias. Madrid: Librería General de Victoriano Suárez, 5t.

Portilla, León. 1997. El destino de la palabra. México: Fondo de Cultura Económica.

Rodrigues, Aryon Dall'Igna. 1986. Linguas brasileiras; para o conhecimento das línguas indígenas. São Paulo: Loyola.

Rouillon, José Luiz. 1997. Antonio Ruiz de Montoya y las reducciones del Paraguay. Asunción: Centro de Estudios Paraguayos "Antonio Guasch".

. 1991. Introducción, transcripción y notas al Sílex del divino amor. In: Antonio Montoya. [1650] 1991:7-111.

Soares, André. 1997. Guarani: organização social e arqueologia, Porto Alegre: EDI PUCRS.

Susnik, Branislava. 1986/87. Lenguas Chaqueñas. "Los Aborígenes del Paraguay" I. VII/1. Asunción: Museo Etnográfico Andrés Barbero.

1982. Los aborígenes del Paraguay. IV. Cultura Material. Asunción: Museo Etnográfico "Andrés Barbero".

Varnhagen, Francisco Adolfo de. [1857]. 1964. História Geral do Brasil, 8. São Paulo: Melhoramentos. 
Zwartjes, Otto (ed.). 2000. Las gramáticas misioneras de tradición hispánica (Siglos XVIXVII). Amsterdam/Atlanta: Rodopi.

Data recebimento: $05 / 11 / 2014$

Data aceite: $20 / 11 / 2014$ 